\title{
Predictable Patterns and Their Corresponding Signal Sources of Midsummer Surface Air Temperature Over Eastern China in the ECMWF S2S Forecasts
}

\author{
Zikang Jia \\ Lanzhou University \\ Zhihai Zheng ( $\nabla$ zhengzh@cma.gov.cn ) \\ Lanzhou University \\ Yufan Zhu \\ Lanzhou University \\ Naihui Zang \\ Lanzhou University \\ Guolin Feng \\ CMA: China Meteorological Administration \\ Bicheng Huang \\ Lanzhou University
}

\section{Research Article}

Keywords: Eastern China, Midsummer T2m, Predictable patterns, ECMWF S2S forecast

Posted Date: October 29th, 2021

DOI: https://doi.org/10.21203/rs.3.rs-999090/v1

License: (a) (i) This work is licensed under a Creative Commons Attribution 4.0 International License.

Read Full License 


\section{Predictable patterns and their corresponding signal sources of midsummer surface air temperature over Eastern China in the ECMWF S2S forecasts}

Zikang Jia $^{1}$ Zhihai Zheng ${ }^{1,2}$ Yufan Zhu ${ }^{1}$ Naihui Zang ${ }^{1}$ Guolin Feng ${ }^{2}$ Bicheng Huang ${ }^{1}$

5 Abstract The maximum signal-to-noise empirical orthogonal function (MSN EOF) method is used to evaluate the midsummer 2-m air temperature (T2m) over Eastern China of subseasonal to seasonal scale forecast data in ECMWF model, and investigate the underlying mechanisms between temperature modes and predictable sources. The first predictable pattern mainly presents the dipole mode of positive value in the south and negative value in the north. The model captures the signal of the transition from preceding El Niño to La Niña and accompanying tropical Indian Ocean warm surface temperature. In the summer of transforming years, the West Pacific Subtropical High is stronger and westward, meanwhile the southwest monsoon strengthens, which are the main direct influence factors of the high pressure in the south and the more precipitation in the north. Compared with observations, although the model captures the relationship between the temperature mode and the previous sea surface temperature signal, it obscures the mediating role of the Western Pacific Subtropical High. The second predictable pattern is the warmer characteristic of the Yangtze River valley (YRV), and North Atlantic Oscillation which the atmospheric internal variability is the main signal. The wave train propagating from northwestern Russia to Northeast Asia is the main cause of the abnormal high pressure over YRV. The third mode is mainly the temperature trend item, and the spatial characteristics of observation and model are quite different. ECMWF model shows high forecasting skills in the three modes, and presents high (low) surface pressure in areas with high (lower) temperatures, reduced (increased) precipitation and increased (reduced) solar radiation, which proving the model simulates the potential mechanism of circulation anomalies affecting surface air temperature commendably. Keywords Eastern China $\cdot$ Midsummer T2m $\cdot$ Predictable patterns $\cdot$ ECMWF S2S forecast

\section{Introduction}

\section{Zhihai Zheng}

zhengzh@.cma.gov.cn

1 College of Atmospheric Science, Lanzhou University, Lanzhou, China

2 Laboratory for Climate Studies, and National Climate Center, China Meteorological Administration, Beijing, China 
In the context of global warming and climate change, heat waves (HWs) have shown an obvious trend of growth. HWs have large impacts such as harming human health, aggravating energy consumption, destroying ecological environment, and so on, which become important meteorological and climatic disasters, drawing more attention in recent years (Easterling et al. 2000; Rey et al. 2009; Coumou and Rahmstorf 2012; Papalexiou et al. 2018). For instance, the European HW in 2003 and the Russian HW in 2010 both caused huge casualties and property losses which immediately attracted a large number of researchers to explore their causes and to establish extreme HW prediction systems (Fouillet et al. 2006; Barriopedro et al. 2011). Eastern China (EC) is coastal area which densely populated, economically developed, and very sensitive to extreme disasters. Such in the summer of 2013, the sustained HW in the Yangtze River valley (YRV) caused more than 5,500 deaths and a direct economic loss of 59 billion yuan (Zhang et al. 2014; Gu et al. 2016). Recent researches show that the air temperature and HWs in EC have a continuous increasing trend, and extreme high-temperature events (EHTEs) are mainly concentrated in midsummer (Sun et al. 2014; Guo et al, 2017). Therefore, it is particularly important to understand the predictable sources of midsummer air temperature in EC and to predict them timely and accurately.

Abnormal temperature events such as EHTEs often require more advanced warning to provide the government with response measures and sufficient time for the people to take refuge. The World Weather Research Program and the World Climate Research Program jointly initiated the subseasonal to seasonal (S2S) prediction program with the aim of improving the S2S-scale forecast skills and analyzing its physical mechanism, a total of 11 members have participated this program and provided forecast data. S2S-scale prediction program fills in the gap between the weather and subseasonal forecasts (Vitart et al. 2017; White et al. 2017). Due to the disappearance of atmospheric initial conditions and the delay of boundary conditions, forecast models are difficult to distinguish clear signal sources. The elusive non-linear processes of multiple scales also hinder the prediction. Consequently, the current research on the S2S models shows that the weather scale forecast skills within 2 weeks are high. The skills deviations on extended period between different models are large, and individual models still have high forecast skills on the time scale of about 4 weeks. For example, Andrade et al. (2018) showed that ECMWF, UKMO and KMA had high precipitation forecast skills on a global scale, but that declined rapidly after the 
second week. Zhou et al. (2019) found that ECMWF had the highest forecast skills for winter 2-m air temperature (T2m) in China, its skillful duration was 2-4 weeks, and the forecast score presented differences in space which northern region was higher than that of the southern region. Exploring the predictable sources of the S2S model is an important direction for understanding the subseasonal process and improving forecast. The predictable sources of the S2S time scale mainly include Madden-Julian Oscillation (MJO), atmospheric quasi-biweekly oscillations and other long-lasting atmospheric initial conditions; boundary conditions such as sea surface temperature (SST), soil humidity, ice and snow conditions; others like atmospheric teleconnection, interaction between atmospheric layers, etc. What are the driving factors and physical mechanisms of the temperature mode in S2S-scale, whether the signals obtained in observational research can be reproduced in the model, or whether the model has false signals that do not exist in the observations, these issues deserve more attention.

As our main research area, EC has a vast territory and a complex circulation system. Its air temperature in summer is affected by different systems or multiple systems, which blurred the predictions of numerical models. Western Pacific Subtropical High (WPSH), an important member of the East Asian summer monsoon, is the most important factor affecting the air temperature over EC. When it becomes significantly stronger and westward, the abnormally high temperature will appear in the high-pressure control area, and its north-south position controls the 75 high and low temperature ranges and rain bands (Wang et al. 2016; Deng et al. 2019). Southwest monsoon and atmospheric quasi-biweekly oscillations are two other decisive circulation systems affecting the air temperature in South China (SC) (Chen and Lu, 2015; Chen et al. 2017). The location and intensity of the East Asian subtropical jet and the South Asian high affect north-south and east-west shifts of the high air temperature zone in north central China (Wang et al.2013).

80 These circulation anomalies usually have more advanced signals such as that the WPSH is considered as a bridge connecting El Niño to the East Asian climate. In the summer of El Niño decaying years, the stronger WPSH cause the higher air temperature in SC (Wang et al.2017; Deng et al.2019). In addition, the equatorial Indian Ocean capacitor effect affects the SC to Jianghuai region by exciting the abnormal Kelvin wave to strengthen the anticyclone over western Pacific (Xie et al.2009). Atlantic sea surface temperature anomalies (SSTAs) from winter to summer can affect the summer temperature in northern China through atmospheric circumglobal 
teleconnection (CGT) or North Atlantic-Eurasian teleconnection (Li and Ruan 2018; Li et al.

2019). In order to explore whether the S2S model can capture the complex multi-system signals and reproduce the underlying mechanisms, we use the ECMWF model forecasts with the highest forecast skills in the S2S program to study the main surface air temperature predictable patterns over EC in midsummer and corresponding predictable sources.

Maximum signal-to-noise empirical orthogonal function (MSN EOF) is one of the effective methods to extract model predictable patterns (predictable components). This method is developed by Allen and Smith (1997), and applied by Huang (2004), Hu and Huang (2007) and Liang et al. (2009). MSN EOF can maximize signal-to-noise ratio in limited members, reduce random errors, eliminate unpredictable parts, and obtain predictive patterns, which is effective method to solve the problems mentioned above. Therefore, this paper uses this method to study the above questions. The structure of this paper is as follows: The data and method used in this study are in section 2. The forecast skills and predictable patterns of the ECMWF model are showed in section 3. Section 4 discussed the corresponding physical mechanism. Summary and discussion are provided in section 5 .

\section{Data and method}

ECMWF-S2S forecast data is issued by European Centre for Medium-Range Weather Forecasts (ECMWF) which includes real-time forecast and hindcast. The real-time forecast started in 2015 , which is a $0-46 \mathrm{~d}$ integration. Its horizontal resolution is T639/319 $\left(0.25^{\circ} \times 0.25^{\circ}\right.$ before day $10,0.5^{\circ} \times 0.5^{\circ}$ after day 10), a total of 91 layers in the vertical direction (L91), and twice a week for forecast frequency. The ensemble members include a control experiment member and 50 perturbed experiment members (perturbed atmospheric initial conditions). The hindcast data is flying, which the model returns the past 20 years hindcast data after each real-time forecast. Its resolution, forecast frequency and forecast time are the same as the real-time forecast, but the ensemble members include a control member and 10 perturbed members. The model is air-sea coupling but not sea-ice coupling.

This article mainly focuses on the eastern part of China $\left(18^{\circ}-42^{\circ} \mathrm{N}, 105^{\circ}-123^{\circ} \mathrm{E}\right)$ in the midsummer that EHTEs occur frequently. In order to better analyze statistical result and ensure the consistency of the data, the data in this paper adopted the real-time forecast data in 2019 and the 
hindcast data for the 2019 version (1999-2018). The ensemble members include a control member and 10 perturbed members. Because our research period focuses on midsummer, we only utilized each first data in July. Previous studies show that model's forecast skills declined sharply after the fourth week , 0-30 d average data is select to obtain the predictable pattern. Observed data used for verification are from the fifth-generation atmospheric reanalysis data of ECMWF (ERA5). Because SST is a variable that changes slowly, so ERA5 SST is used to analyze the external forcing instead of model forecast SST. SST and circulation indexes are issued by the National Climate Center of China. All data have been processed to remove the 21 years average (19992019).

MSN EOF is the main analysis tool applied in this study to extract the model predictable patterns developed by Allen and Smith (1997). It is same as mentioned by Venzke et al. (1999). A simple introduction and algorithm will be given below, and the specific principle can be referred to the above literature. Assuming an infinite number of ensemble members predicted by the model, the ensemble mean of the members can be regarded as the unbiased signal of the model because the unknown random error of each member's forecast has been eliminated. However, in reality, the number of members is limited, therefore ensemble mean cannot completely eliminate this internal random error. How to maximize the elimination of this error is the key. The first mode of MSN EOF can maximize the ratio of signal (ensemble mean) and noise (the deviation between members), and the second mode maximizes this ratio while is orthogonal to the first mode...Similar to traditional EOF, MSN EOF also decompose the forecast sets into spatialtemporal distributions. In this study, the time dimension of the model forecast sets is 21 years, a total of 11 ensemble members, and the spatial area are selected at $18-42^{\circ} \mathrm{N}$ and $105-123^{\circ} \mathrm{E}$ with a total of 221 points. The specific operations are as follows:

Denote by $\boldsymbol{X}_{\boldsymbol{k}}$ a model member forecasts at a fixed lead time:

$$
X_{k}=X_{M}+X_{k}^{\prime}
$$

$\boldsymbol{X}_{\boldsymbol{M}}$ represents the ensemble mean, $\boldsymbol{X}_{\boldsymbol{k}}^{\prime}$ represents the deviation from the ensemble mean, $\mathbf{k}=$ $\mathbf{1 , 2}, \ldots \mathrm{K}$ represent different ensemble members. If the ensemble has an unlimited number of members, then the ensemble mean can well eliminate the random error, the expectations of $\boldsymbol{X}_{\boldsymbol{M}}$ 
$\left(\mathbf{E}\left(\boldsymbol{X}_{\boldsymbol{M}}\right)\right)$ is the complete signal to be sought. Assuming that $\boldsymbol{X}_{\boldsymbol{M}}$ can be decomposed into predictable and unpredictable components:

$$
X_{M}=X_{P}+X_{R}
$$

$\boldsymbol{X}_{\boldsymbol{P}}$ is the common "signal" in all members. $\boldsymbol{X}_{\boldsymbol{R}}$ is the random "noise" in individual members. Predictable patterns are the leading modes of $\boldsymbol{X}_{\boldsymbol{P}}$ by EOF.

Assuming that $\boldsymbol{X}_{P}$ and $\boldsymbol{X}_{\boldsymbol{R}}$ are temporally uncorrelated with each other, then the covariance matrix $\left(\boldsymbol{C}_{\boldsymbol{M}}\right)$ of $\boldsymbol{X}_{\boldsymbol{M}}$ can be decomposed into the the signal and noise covariance matrices:

$$
C_{M}=C_{P}+C_{R}
$$

Suppose there is a matrix $\boldsymbol{F}$ such that $\boldsymbol{F}^{\boldsymbol{T}} \boldsymbol{C}_{\boldsymbol{R}} \boldsymbol{F}=\boldsymbol{I}$, which $\boldsymbol{I}$ is the identity matrix. This transformation is called the "prewhitening". In actual calculation, $\boldsymbol{F}$ is constructed from the first $\mathbf{Y}$ weighted EOF patterns of $\boldsymbol{X}_{\boldsymbol{k}}^{\prime}$ (Combine time dimension and member dimension into one dimension). $\mathbf{Y}$ is chosen as 21 here because the time dimension size of hindcast.

Next, project $\boldsymbol{X}_{\boldsymbol{M}}$ into the first $\mathbf{Y}$ modes of the noise matrix $(\boldsymbol{F})$, obtaining prewhitening forecast data $\boldsymbol{X}_{\boldsymbol{M}}^{\prime}$. In order to construct a physical space filter matrix $\widetilde{\boldsymbol{E}}$, first calculate a singular value decomposition (SVD) for $\boldsymbol{X}_{\boldsymbol{M}}^{\prime}$, getting the left matrix $\boldsymbol{E}^{\prime}$, then: $\widetilde{\boldsymbol{E}}=\boldsymbol{F} \boldsymbol{E}^{\prime}$. Each column vector $(\widetilde{\boldsymbol{e}})$ in $\widetilde{\boldsymbol{E}}$ is filter vector, the first one maximizes the ratio of the variances of the ensemble mean and within-ensemble deviations. The first MSN EOF principal component (PC1) is obtained by projecting $\boldsymbol{X}_{\boldsymbol{M}}$ onto the $\tilde{\boldsymbol{e}}_{\mathbf{1}}$.

$$
P C_{1}=\frac{X_{M}^{T} \tilde{e}_{1}}{\lambda_{1}^{\prime}}
$$

Where $\lambda_{1}^{\prime}$ represents the first element in the diagonal matrix of SVD for $\boldsymbol{X}_{\boldsymbol{M}}^{\prime}$. The first MSN EOF (predictable pattern) is obtained by projecting $\boldsymbol{X}_{\boldsymbol{M}}$ onto the PC1:

$$
e_{1}=\frac{X_{M} P C_{1}}{\lambda_{1}^{\prime}}
$$

The second pattern can be determined accordingly which is orthogonal to the first pattern......

The significance test method of the predictable patterns comes from Venzke et al. 1999. Suppose there is no real signal for a certain mode, the ratio of the variance $\left(\sigma_{M}^{2}\right)$ of the time series $\left(\mathbf{Y}_{\mathbf{M}}\right)$ by projecting $\boldsymbol{X}_{\boldsymbol{M}}$ onto $\tilde{\boldsymbol{e}}$ and the averaged within-ensemble variance $\left(\boldsymbol{\sigma}_{\boldsymbol{N}}^{2}\right)$ of the time series $\left(\mathbf{Y}_{\mathbf{K}}\right)$ by projecting $\boldsymbol{X}_{\boldsymbol{K}}$ onto $\tilde{\boldsymbol{e}}$ obeys an $\mathbf{F}$ distribution:

$$
n \frac{\sigma_{M}^{2}}{\sigma_{N}^{2}} \sim F_{m-1,(m-1)(n-1)}
$$


$\mathbf{m}$ and $\mathbf{n}$ are the number of time samples and ensemble members respectively.

\section{Spatiotemporal characteristics and MSN EOF of Jul T2m in Eastern China}

\subsection{Climatology, standard deviations, and trends}

Fig. 1 shows mean July T2m in observations (Obs) and forecasts of ECMWF during 1999-

2019. In observed pattern, the average temperature in the middle and lower reaches of the Yangtze River to the central and southern regions exceeds $30^{\circ} \mathrm{C}$, which is the region with the highest temperature in EC. The average temperature in parts of southern China is around $27-28^{\circ} \mathrm{C}$, and climatological normal in western part of North China is relatively low, about $23-24^{\circ} \mathrm{C}$. Compared to Obs, the observed pattern is well predicted in ECMWF. The locations of the highest and lowest climatic temperatures in the model are consistent with the Obs, but the model shows cold biases in most areas especially in higher temperatures portion.

The standard deviation of ECMWF forecast $\mathrm{T} 2 \mathrm{~m}$ is compared with that of Obs which are used to measure interannual variability (Fig. 2). The most notable feature in Obs is that large standard deviation mainly ranges from the middle and lower reaches of the Yangtze River to the central and southern regions. Compared to Obs, the ECMWF forecast has a significantly smaller standard deviation, with about $0.5-1{ }^{\circ} \mathrm{C}$ bias in the maximum value area. This may be due to ECMWF forecast significantly underestimates the mean temperature and interannual variability. Both Obs and the model show that the highest climatic temperature region is consistent with the region with the largest interannual variability.

Fig. 3 shows the trends of T2m in July based on Obs and ECMWF forecasts. The model underestimated warming the trend in Huang-Huai area, and overestimated the warming trend in Northern China and most of South China, indicating a opposite trend in most of Eastern China. Especially in the northern part of North China, it is a significant cold trend in the observation, while a significant warm trend in the model. Furthermore, the warming trend in model is clearer than observation. 
(a) obs

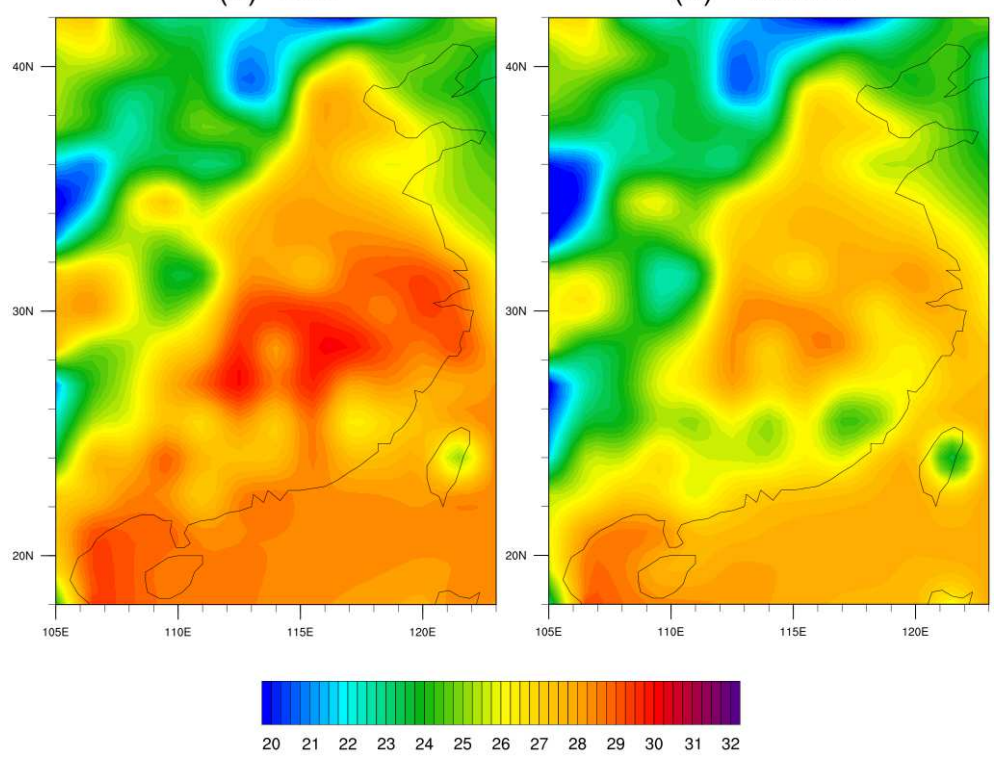

Fig.1 Mean 2-m air temperature (T2m) in July in (a) observations and (b) forecasts of ECMWF during 1999-2019. (Units: ${ }^{\circ} \mathrm{C}$ )

(a) ERA5

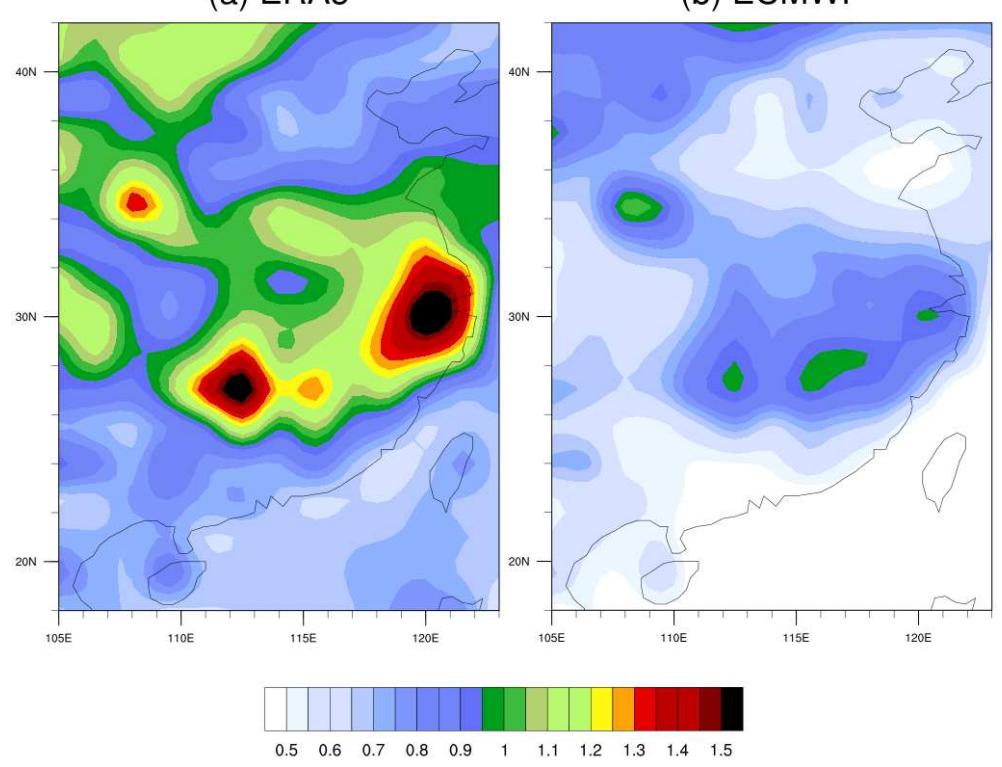

Fig.2 Same as Fig.1 but for standard deviations. 
(a) ERA5

(b) ECMWF

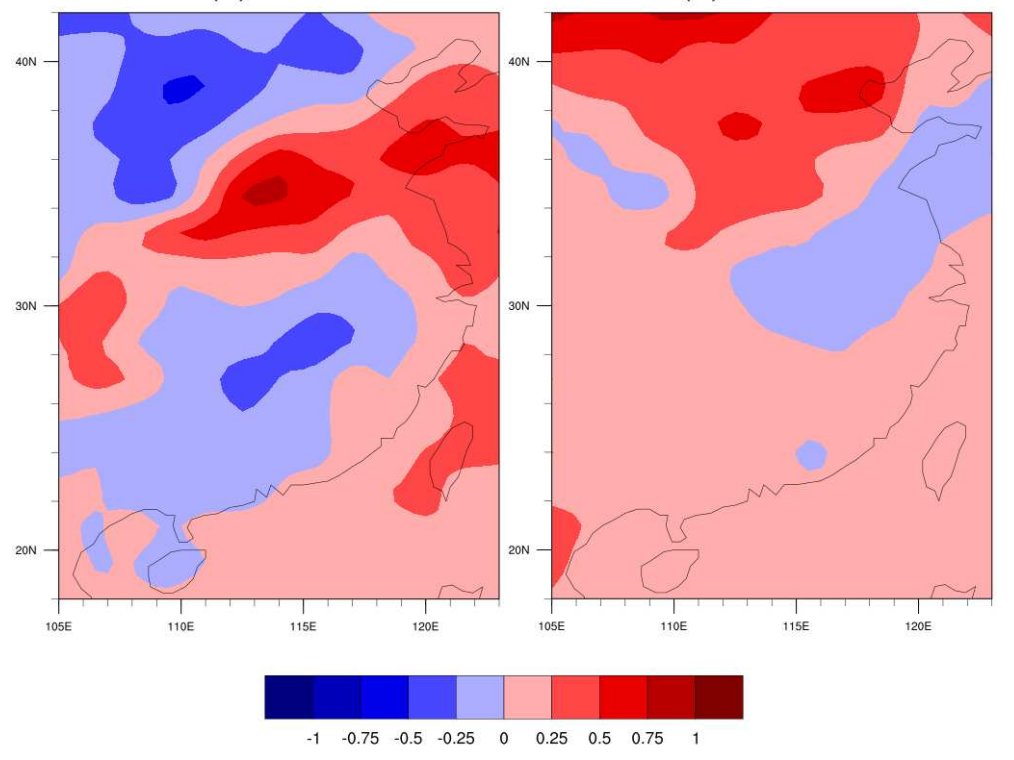

Fig.3 Same as Fig.1 but for trends (Units: $\left.{ }^{\circ} \mathrm{C} / 10 \mathrm{a}\right)$.

\subsection{Most predictive patterns}

The predictable patterns of T2m in EC are extracted by applying MSN EOF. We discuss the leading three most predictable patterns, since only these exceed the significance at $95 \%$ confidence level (F test). Fig. 4a is the first MSN EOF mode (MSN EOF1), which explains $22.4 \%$ of the total variance. The first mode reflects the dipole of north-south reverse orientation near $30^{\circ} \mathrm{N}$. The corresponding time series (Fig. $4 \mathrm{~b}$, black curve) have obvious interannual change characteristics. Since the MSN EOF mode is only characterized by the calculation of model forecast data, in order to cross-check whether the most predictable pattern of MSN EOF1 exist in real, we examined the similarity between the time series computed by projecting the ensemble mean of the model forecasts onto MSN EOF1 (PC1) and by projecting the observed data onto MSN EOF1 (oPC1). The correlation between the two series is 0.77 , which significantly exceeds the $95 \%$ confidence level, and both two series (PC1, oPC1) have obvious interannual change characteristics. Although the amplitude of time series in model and Obs are relatively consistent, the explained variance is quite different. MSN EOF1 explains more variance within the model than in the Obs, which is likely due to the underestimated standard deviations in the model (Fig. 2). In order to assess whether the oPC1 mentioned previously is affected by any possible systematic bias of the model, we obtained the spatial mode by the regressing Observed T2m onto the PC to examine the relationships between the first mode and observed T2m pattern. Fig. 5a 
presents the consistency of the first predictable pattern and observed $\mathrm{T} 2 \mathrm{~m}$ in the north-south dipole signal, and the positive and negative centers are similar to Fig. 4a (pattern correlation coefficient $(\mathrm{pcc})=0.92)$, which testifies the authenticity of PC1.

Fig. $4 \mathrm{c}$ shows the second predictable pattern which explains $17.1 \%$ of the total variance. The most conspicuous feature in this mode is a positive anomaly zone from the Yangtze River to the Yellow River. The high correlation between PC2 and projected observed time series oPC2 (cor $=0.76$ ) shows authenticity and the predictability of the second predictable pattern for ECMWF model. The difference between explained variances in model and observation is visible, which may be affected by the same reason of MSN EOF1. The observed signal associated with the second predictable mode (Fig. 5b) has the same positive anomaly zone with Fig. 4c, which the critical area exceeds $95 \%$ confidence level of $t$ test.

Fig. 4e-f show the third predictable pattern and corresponding time series. Although this mode has obvious positive and negative regions and different spatial characteristics from the first two modes, the noticeable features are the small interannual variability and clear downward trend in PC3. The high correlation between model and Obs time series (Affected by consistent trends) and diffident feature between this predictable pattern and associated observed signals (Fig. 5c) indicate the third predictable patterns may be a temperature trend mode. In order to verify our conjecture, we compared Fig. 4e and Fig. 3b, Fig. 5c and Fig. 3a, and calculated the two pattern correlation coefficients are -0.74 and -0.52 respectively (negative value is due to the decay trend). The similarity between the third predictable pattern and the trend mode confirms our conjecture to a certain extent. 
(a) MSN_EOF 1 (Var_ECMWF $=22.4 \%$ Var_Obs $13.7 \%$ )

(b) PC $1 \quad$ cor $=0.77$
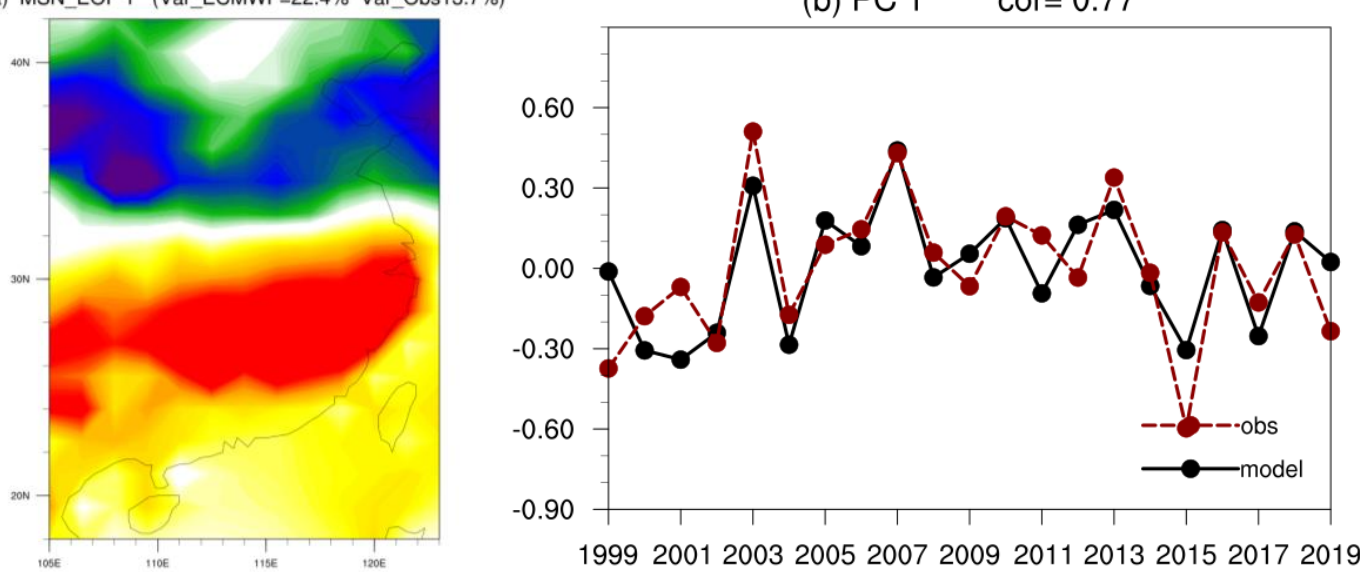

(c) MSN EOF 2 (Var ECMWF $=17.1 \%$ Var Obs $10.2 \%$ )
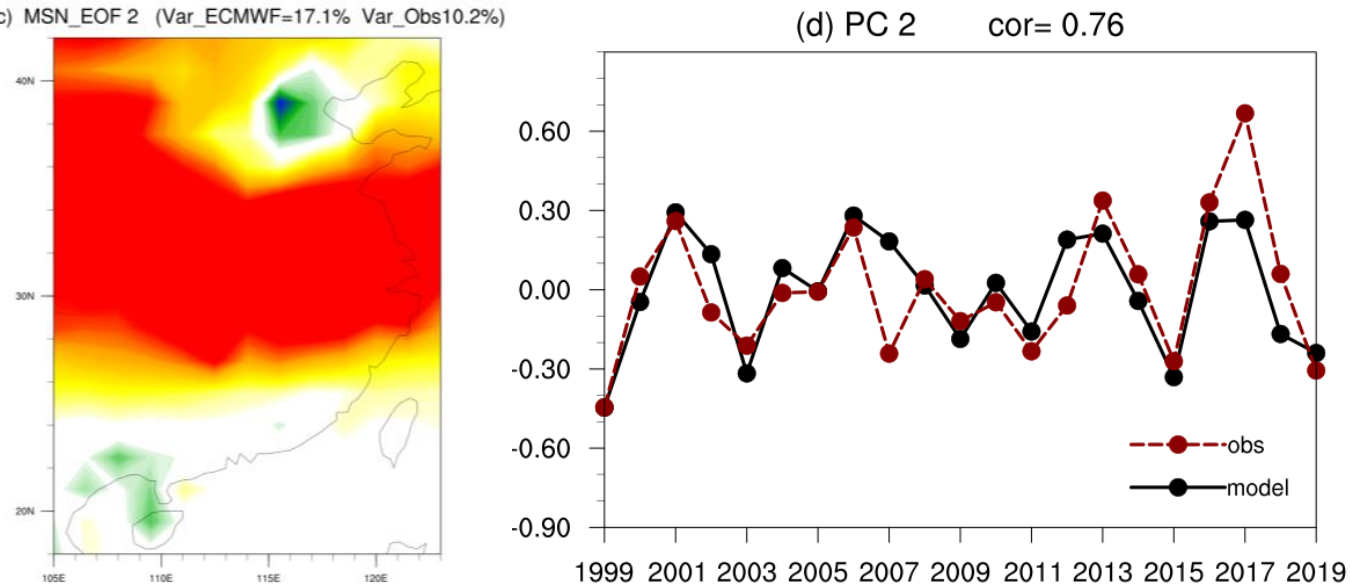

(e) MSN_EOF 3 (Var_ECMWF $=13.5 \%$ Var_Obs $9.2 \%$ )
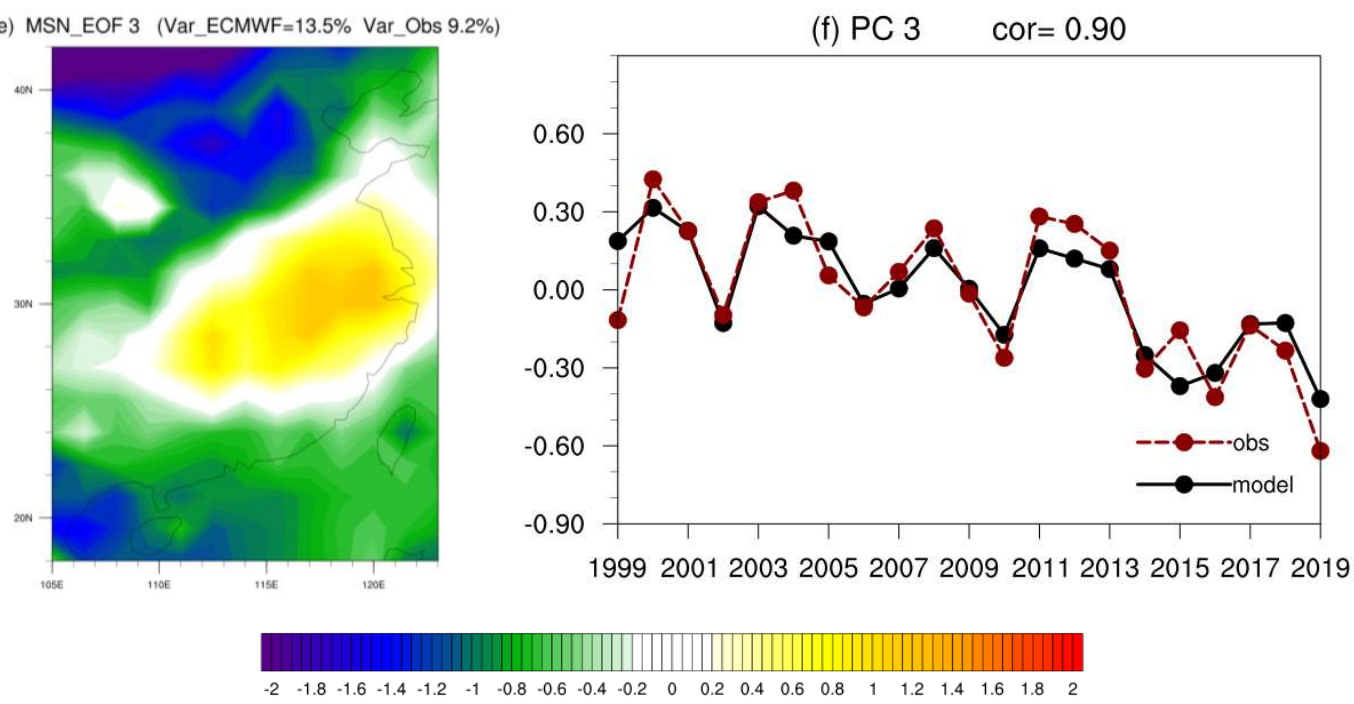

Fig. 4 (a) (c) (e) Leading three MSN EOF modes for Jul T2m forecasted by ECMWF model. (Units: $\left.{ }^{\circ} \mathrm{C}\right)(\mathrm{b})(\mathrm{d})(\mathrm{f})$ The corresponding PC (black solid) and oPC (red dashed) by projecting ensemble mean and observed T2m onto MSN EOF modes. 


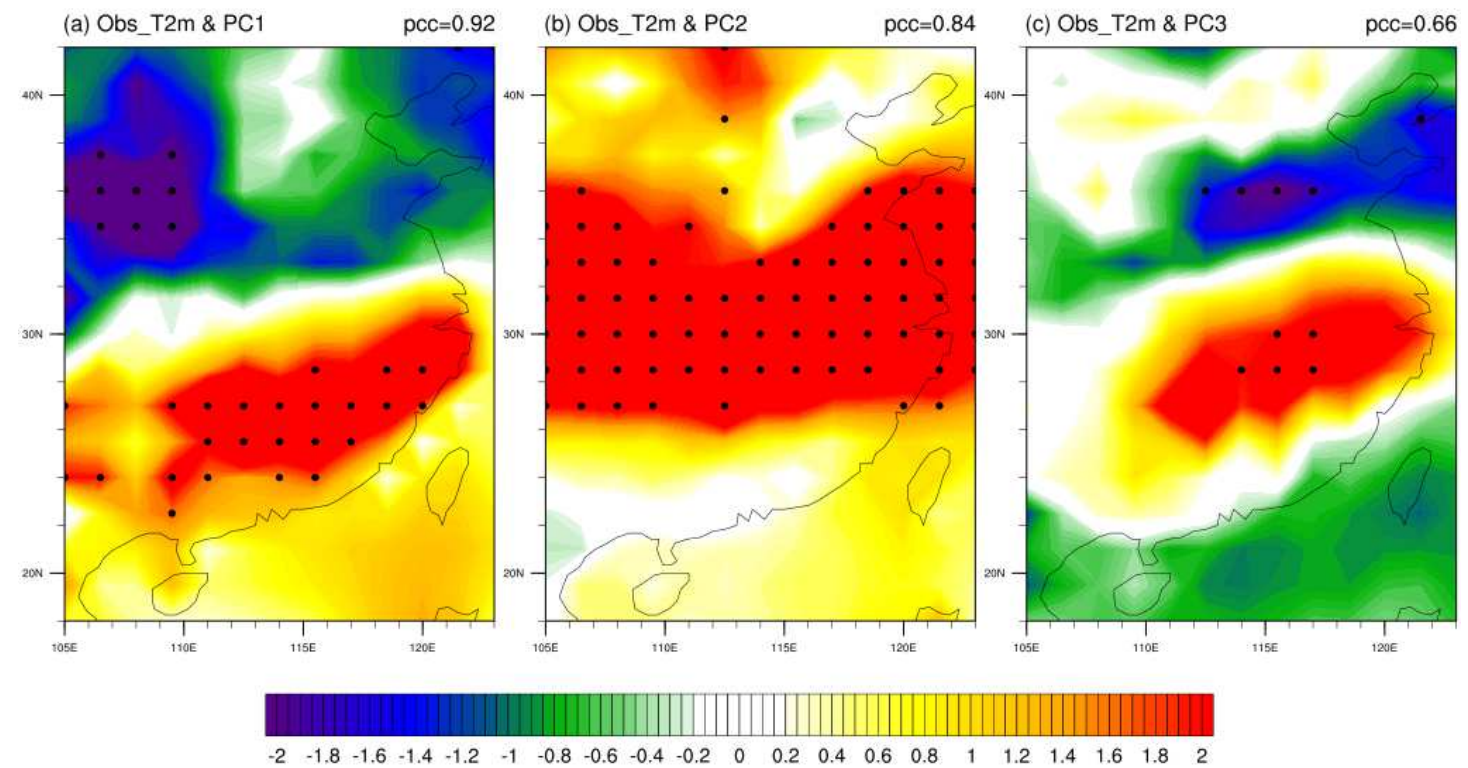

Fig.5 Regression maps of observed T2m onto the first three PCs. (Units: ${ }^{\circ} \mathrm{C}$ ) Stippled areas indicate the anomalies that exceed the $95 \%$ confidence levels.

\section{Drivers and mechanisms}

It is known that the high-pressure and low-pressure systems in the atmosphere are the main factors that affect the high and low temperatures. The anticyclones (cyclones) in the high-pressure (low-pressure) systems and the accompanying sinking (upward) airflow reduce (increase) cloud cover. Sunny (Cloudy) weather will cause the ground to receive more (less) solar radiation, thereby heating (cooling) the surface temperature. On the other hand, this situation means less precipitation and evaporation, so less cloud cover circulates again. (Wang et al, 2017, 2018; Deng, et al, 2019). In order to investigate whether the surface air temperature predictable patterns of the ECMWF model match the anomalies of the circulation, and whether the above physical mechanisms can be reproduced, we analyzed the relationship between the modes and the above factors.

Fig.6 shows the regression maps between PCs and ensemble mean surface pressure (SP), total precipitation (TP) and solar short downward radiation (SSRD) forecasted by ECMWF model. For the first mode, a gigantic positive anomalous high surface pressure occupies the low latitude area (Fig. 6a), with less TP and more SSRD. The northern area has obvious more precipitation and less solar radiation. Low water vapor conditions from the Bay of Bengal and South China Sea to 
SC are similar to the water vapor conditions of the southwest monsoon that causes high temperatures in SC (Chen and Lu, 2015). For the second mode, there is a strong low pressure over most parts of northern China. More precipitation appears in the NC and SC, and the abnormal dryness in most of the remaining areas including the middle and lower reaches of YRV seems small than positive center in temperature mode. The SSDR shows a similar pattern to MSN EOF2, with significant positive correlations. For the third mode, the correlation with SP is not significant. Less water vapor and positive SSDR anomalies are seen over the southeast China area. These results are consistent with previous conclusion that anomalous high temperature is accompanied the decrease in SSRD and TP. From the analysis of surface pressure, the circulation anomalies related to the first mode are mainly the strong positive pressure in the south, and the second mode is mainly affected by the northern circulation anomalies. The circulation anomalies of trend mode are not obvious, so it is omitted in the subsequent SST external forcing and large-scale circulation analysis 

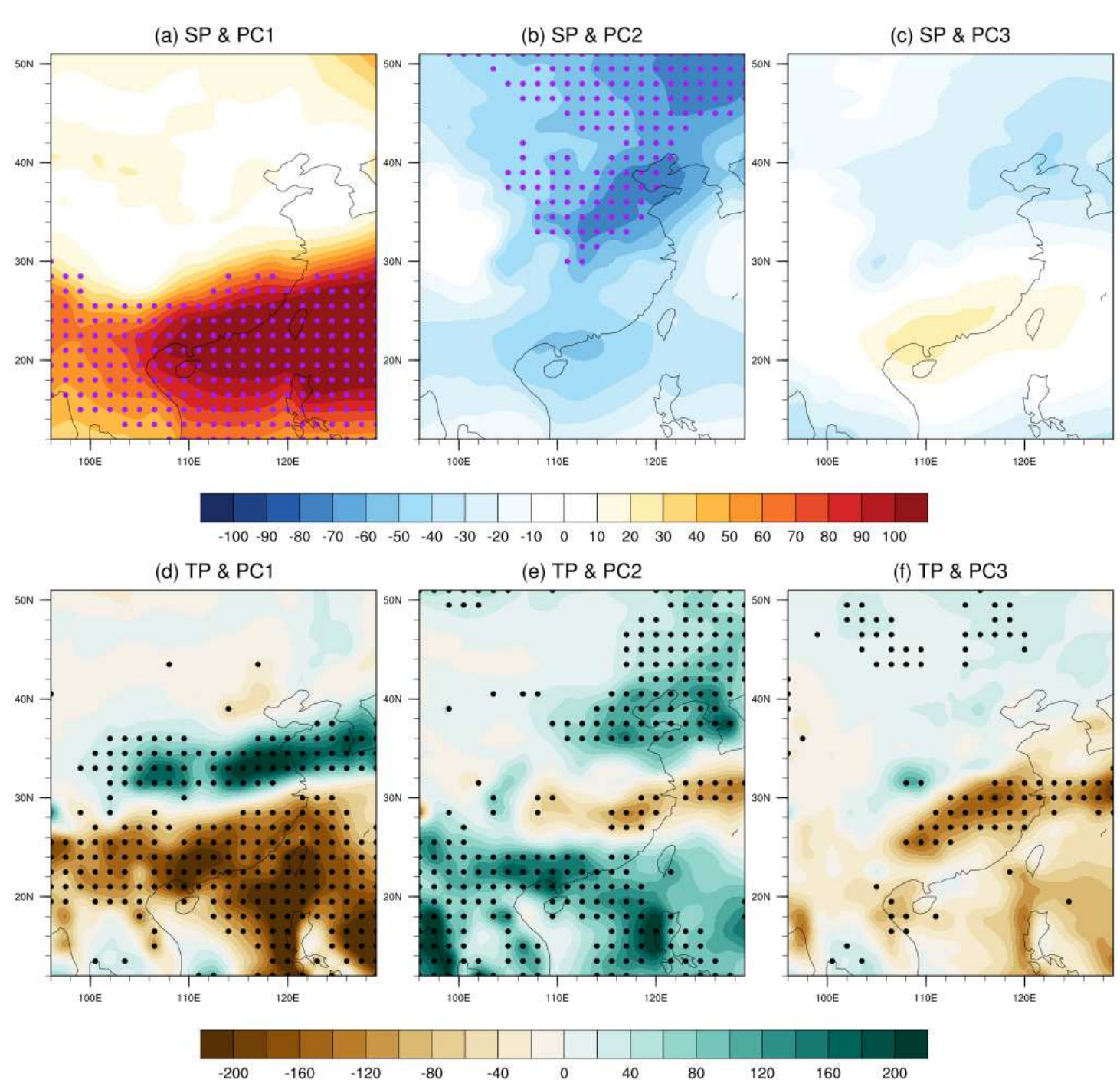

(g) SSRD \& PC1

(h) SSRD \& PC2

(i) SSRD \& PC3

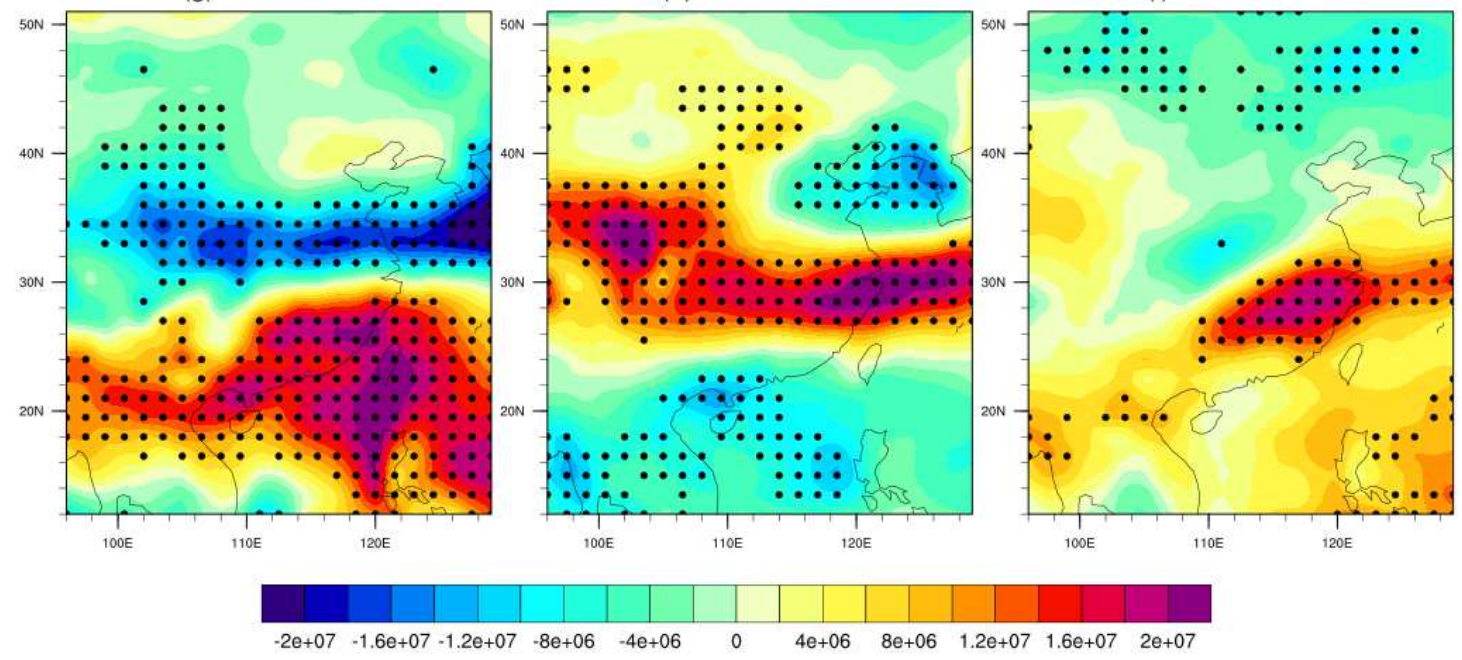

Fig.6 Regression maps of July (a)-(c) surface pressure (SP, Units: Pa), (d)-(f) total precipitation (TP, Units: mm), and (g)-(i) solar short downward radiation (SSRD, Units: $\mathrm{W}^{*} \mathrm{~m}^{-2 *} \mathrm{~s}^{-1}$ ) with (left) 
PC1, (middle) PC2, and (right) PC3 in ECMWF model. Dotted areas indicate that significant values exceeding the $90 \%$ confidence level ( $\mathrm{t}$ test).

What interests us is why the circulation anomalies associated with the T2m predictable modes occur in these regions, what are the early signals and influence processes in ECMWF model, whether these actually exist in the Obs. Fig. 6 shows the regression maps of SST, 500hPa geopotential height (GH500) and wind onto PC1. Because the 5880 line in the GH500 predicted by ECMWF does not appear in the selected area (may be caused by the model deviation), we use the 5860 line instead of the 5880 line to indicate the range of the WPSH. The most obvious characteristic shown in Fig. 7a-c is the abnormally warm SSTAs in the central and eastern Pacific in pre-winter, then the SSTAs gradually disappear in the following spring and summer, which is the typical phenomenon form preceding El Niño to La Niña. Fig. 8a shows the correlation coefficient between the pre-winter NINO3.4 index and PC1 reaching 0.36 , which exceeds the $90 \%$ confidence level, proving that El Niño is the major external force associated with the first predictable pattern. Previous studies have shown that the warm SST in the equatorial eastern Pacific in the pre-winter causes an abnormal anticyclone in the western Pacific in summer through deep convection, hence affecting the climate of East Asia. (Chang et al. 2000; Wang et al. 2000). Regression maps of GH500 (Fig. 7d) verify a positive anomaly of the geopotential height from southeast China to the West Pacific region, simultaneously the WPSH is westward than the climatic stage. The southwest monsoon that west of the anticyclone brings water vapor from the Bay of Bengal and the South China Sea to the area north of the Yangtze River, causing more precipitation in the north which complies with Fig. 6d. The regression maps of circulation anomalies and Nino3.4 (Fig.7e) show consistent characteristics. Although these results are similar to previous studies in Obs, but it is worth noting that this circulation anomalies did not exceed the confidence test. In order to further analyze the specific reasons, we calculated the correlation

315 between the observed and model PCs, the west ridge point of the WPSH index (WPSH_wrpi), and the Nino3.4 index. The high correlation in the Obs (Fig. 8b) is consistent with previous studies, confirming that El Niño caused the temperature anomalies in the first mode by affecting the WPSH. The low correlation between the SSTA and the WPSH in ECMWF (Fig. 8c) shows that the 
model is difficult to reproduce the sea-atmosphere interaction between the WPSH and El Niño,

which obscures the intermediate factors of the WPSH between the first predictable mode and El Niño.

Fig. 7a,b also show abnormally warm SST in equatorial Indian Ocean and equatorial North Atlantic in the early stage. The study of Xie (2009) came up with that in the El Niño decaying year, the warm SST in the equatorial Indian Ocean could strengthen the local deep convection, then propagate to the Western Pacific by baroclinic Kelvin wave, suppress the convection in the Western Pacific and form of an abnormal anticyclone. The correlation coefficient between the prewinter Indian Ocean Basin-Wide index and PC1 reached 0.41, which the significant value is exceeding the confidence level. The abnormally warm SST in the equatorial Atlantic area in spring can also strengthen the WPSH through two ways of affecting the equatorial Indian Ocean to West Pacific easterly wind anomalies and reducing the latent heat in the equatorial central Pacific ( $\mathrm{Lu}$ and Dong, 2005; Hong, et al, 2014). Although both them have a promoting effect on the WPSH, but they also be affected by El Niño. In summary, the predictable source of the first predictable mode in ECMWF is El Niño, but compared to Obs, there is no obvious correlation between SSTAs and WPSH, which may be the key to improving forecasts. 
(a) Reg SST(DJF) onto PC1

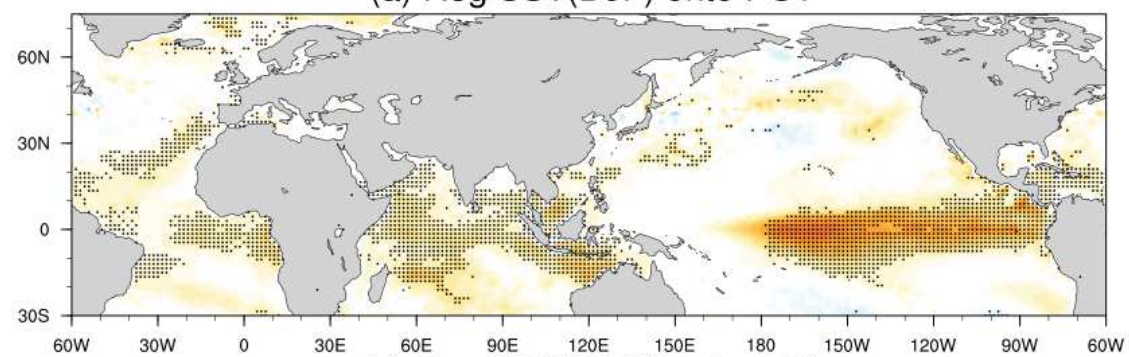

(b) Reg SST(MAM) onto PC1

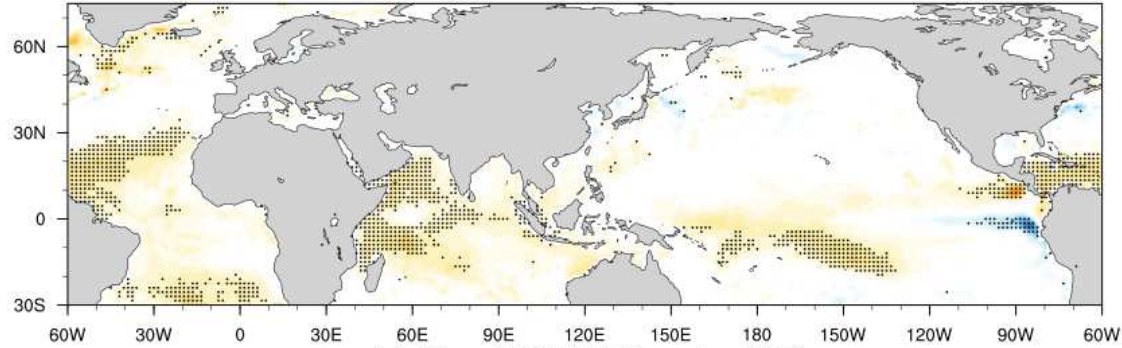

(c) Reg SST(JJA) onto PC1

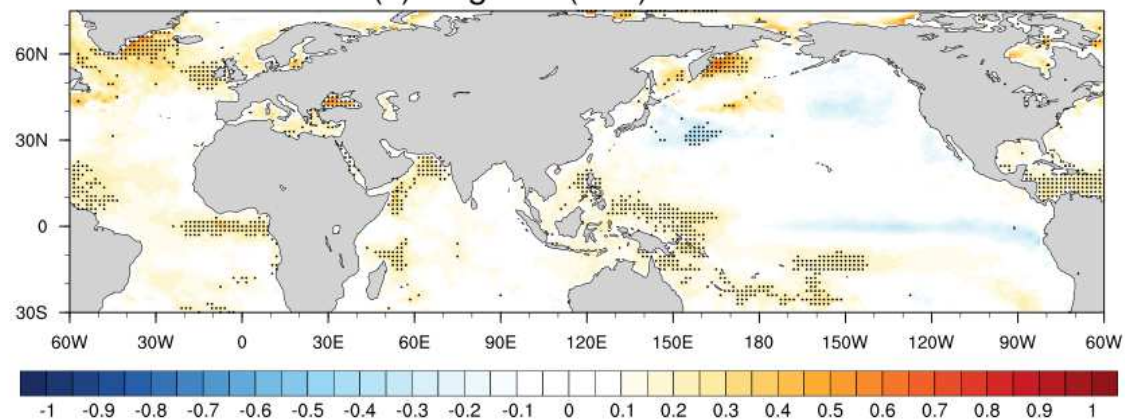

(d) Reg Hgt,U,V onto PC1

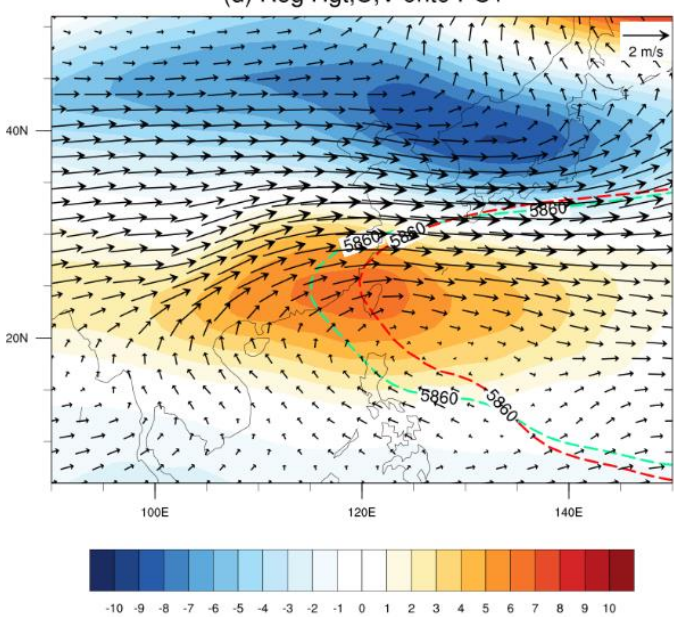

(e) Reg Hgt,U,V onto Nino3.4

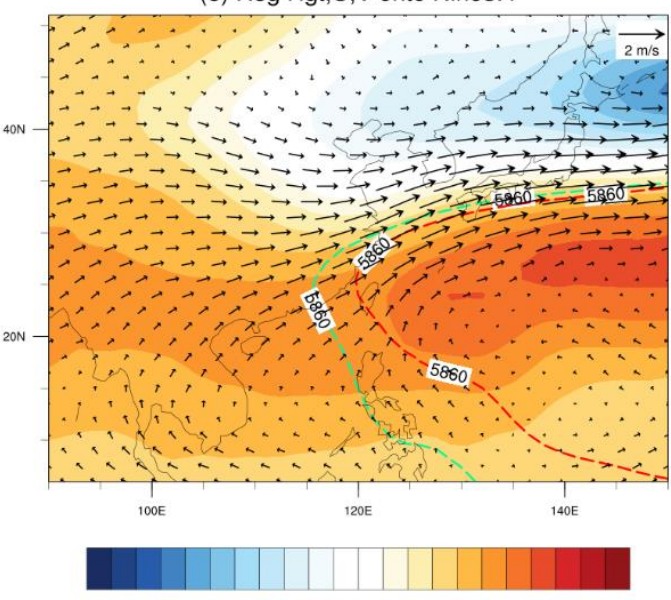

Fig.7 Regression maps of SST (a pre-winter, b spring, c summer) onto PC1(Units: ${ }^{\circ} \mathrm{C}$ ), and regression maps of July GH500 (Units: gpm), wind (Units: $\mathrm{m}^{*} \mathrm{~s}^{-1}$ ) onto the PC1(d) and pre-winter

Nino3.4(e), green dashed for regressed line 5860 and red dashed line for climatic line 5860.

Stippled areas indicate the significant values exceeding the $90 \%$ confidence levels. 
(a) Nino3.4,WPSH_wrpi(ECMWF) \& PC1

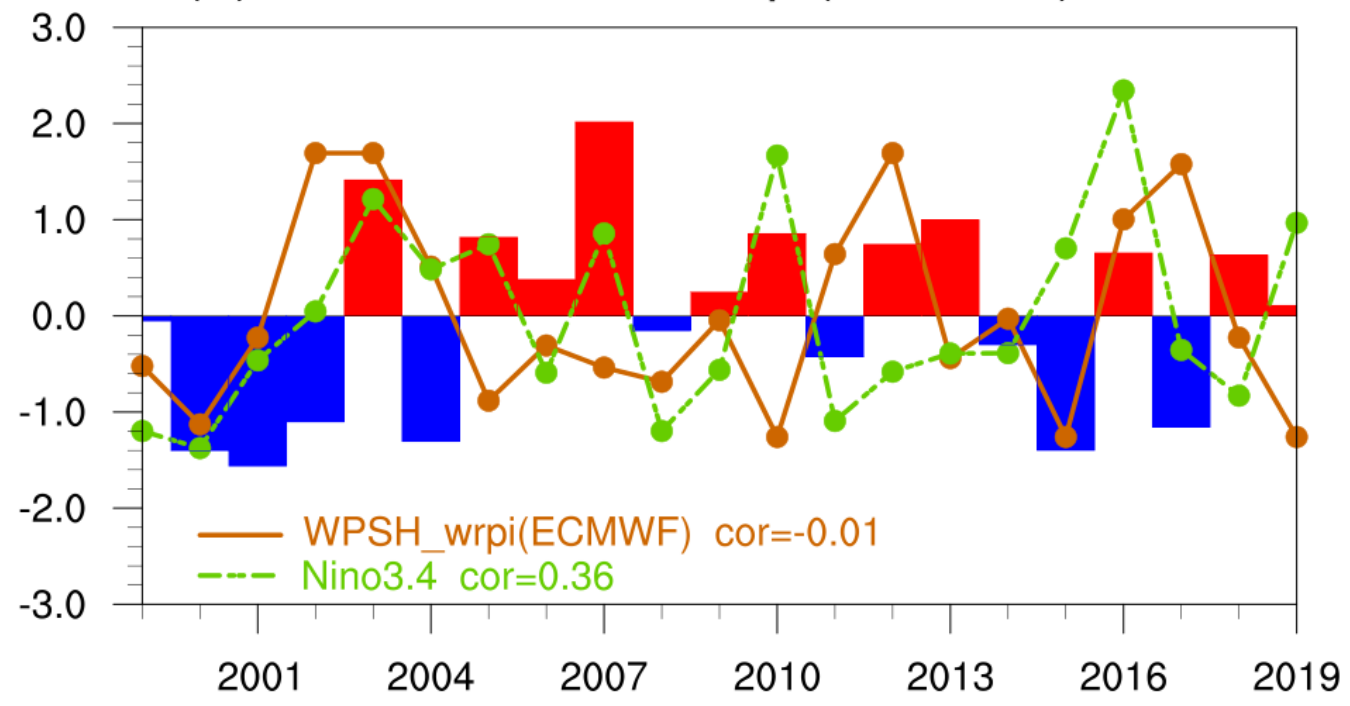

(b) Nino3.4,oPC1 \& WPSH_wrpi(Obs)

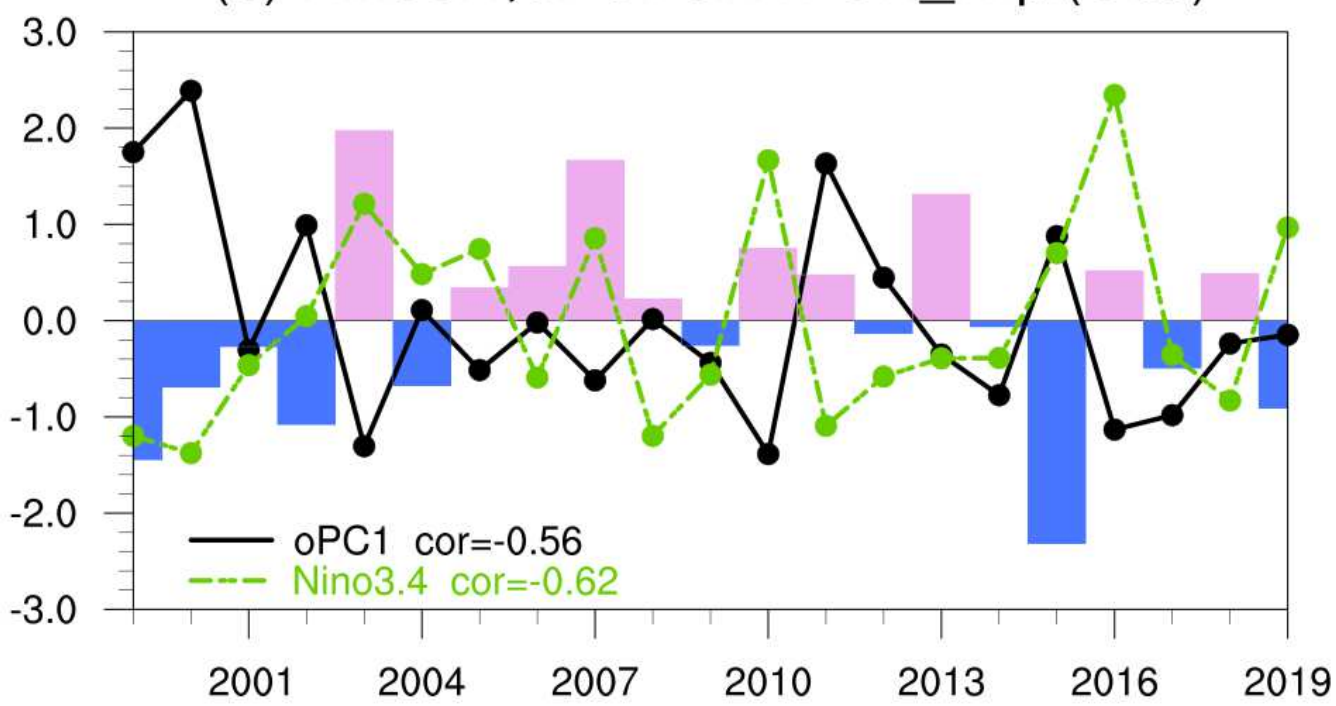


(c) WPSH_wrpi \& Nino3.4

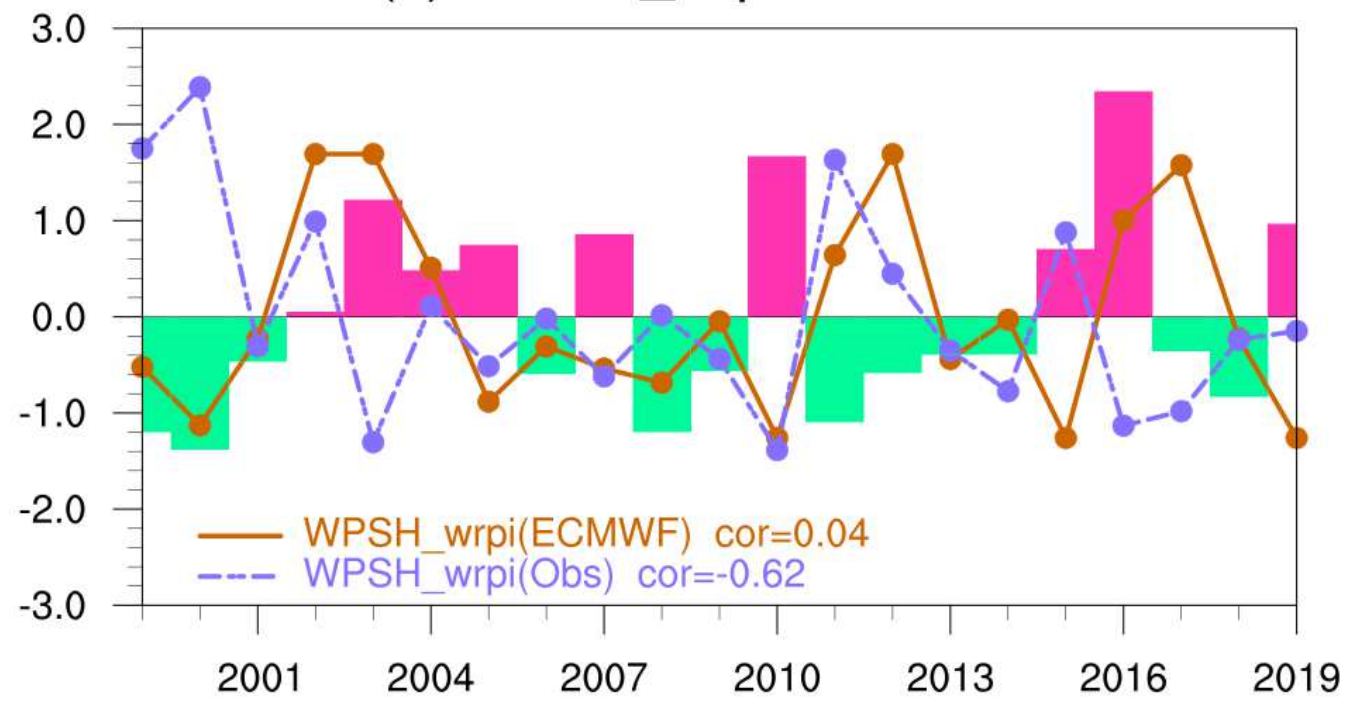

Fig.8 (a) PC1 (bar), the west ridge point of the WPSH index predicted by ECMWF(brown solid ) and pre-winter Nino3.4 index (green dashed) .(b) The west ridge point of the WPSH for Obs(bar) ,oPC1(black solid) and pre-winter Nino3.4 index (green dashed). (c) Pre-winter Nino3.4 index (bar), the west ridge point of the WPSH predicted by ECMWF(brown solid ) and the west ridge point of the WPSH for Obs (blue dashed).

Fig. 9 shows the regression maps of SST onto PC2. Compared with the first mode, there is no obvious SSTA in the second mode. Only some anomalies in the North Atlantic and Northwest Pacific regions during the same period, but they were not obvious from the previous winter to spring. We think these local SSTAs are formed by the response of the atmosphere instead of the previous external forcing signals. Large-scale atmospheric circulation in Fig. 10a prove these SSTA centers correspond to the GH200 anomaly area, and it's interested that the circulation characteristics seem like the circulation mode associated with high air temperature in the YRV mentioned by Deng (2019). As shown in Fig.10a and Deng's study, there is an abnormal lowpressure over the high-latitude North Atlantic Ocean (north of $60^{\circ} \mathrm{N}$ ), meanwhile a high-pressure locating over the mid-latitudes of the North Atlantic Ocean to the north of Russia. And there is a "positive-negative- positive" southeast wave train from northwestern Russia to East Asia. The upper high-pressure center in Northeast Asia affects local lower circulation by baroclinic convection (Deng, et al. 2019). The wave activity flux in Fig. 10a shows the existence of two 
wave propagating from North Atlantic to the northeast and Northwestern Russia to the southeast.

The circulation mode over the North Atlantic which located at the source of the wave train is similar to North Atlantic Oscillation (NAO). Its positive phase presents a positive air pressure anomaly at $30-60^{\circ} \mathrm{N}$ and a negative air pressure anomaly at $60-80^{\circ} \mathrm{N}$ (Ambaum et al. 2001), which same as Fig. 10a. The regression maps of circulation and NAO are consistent with the characteristics of regression maps onto PC2, even the geopotential height anomalies are more obvious. Fig. 10c testifies the correlation coefficient between NAO and PC2 is 0.42 , exceed the $95 \%$ confidence levels, indicating that NAO is the main signal source of the second mode in ECMWF model. The correlation coefficient between NAO and oPC2 is 0.51 , it seems that this signal is more obvious in the Obs.

Although our main focus is July T2m in summer, we also analyzed the data in June and August in June and August (figures not shown). Compared with July, ECMWF's forecasting skills for $\mathrm{T} 2 \mathrm{~m}$ in June and August are lower. However, the predictable patterns and corresponding circulation anomalies have the same characteristics as in July, and El Niño and NAO are still the most important signals. 
(a) Reg SST(DJF) onto PC2

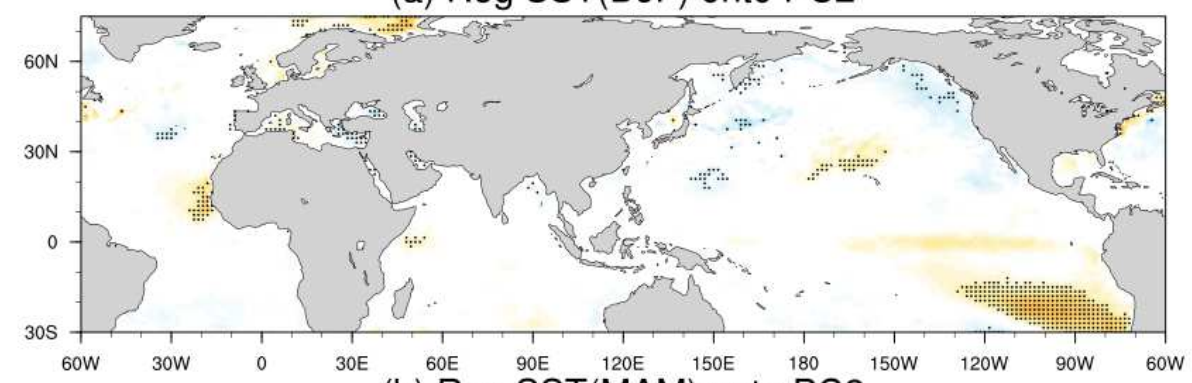

(b) Reg SST(MAM) onto PC2

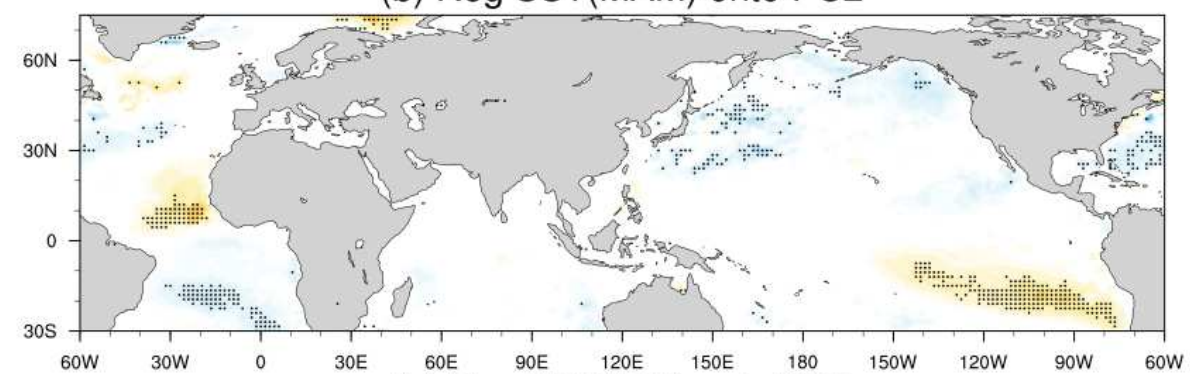

(c) Reg SST(JJA) onto PC2

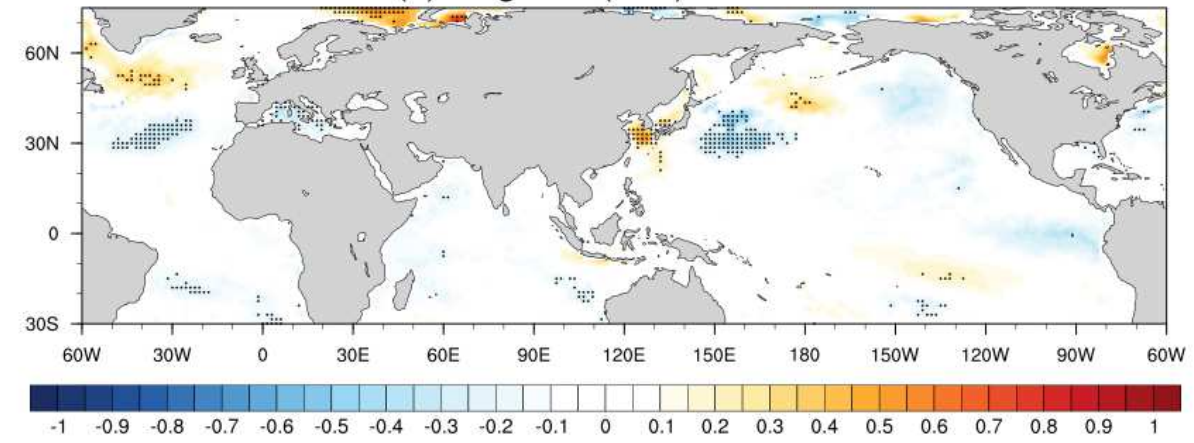

Fig.9 Regression maps of SST (a pre-winter, b spring, c summer) onto PC2 (Units: ${ }^{\circ} \mathrm{C}$ ). Stippled areas indicate significant values exceeding the $90 \%$ confidence levels.

(a) Reg Hgt,WAF onto PC2

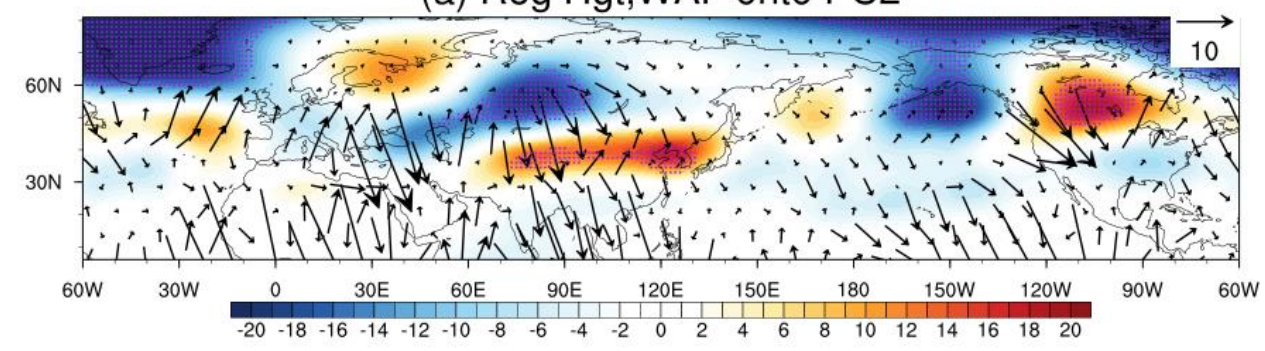

(b) Reg Hgt,WAF onto NAO

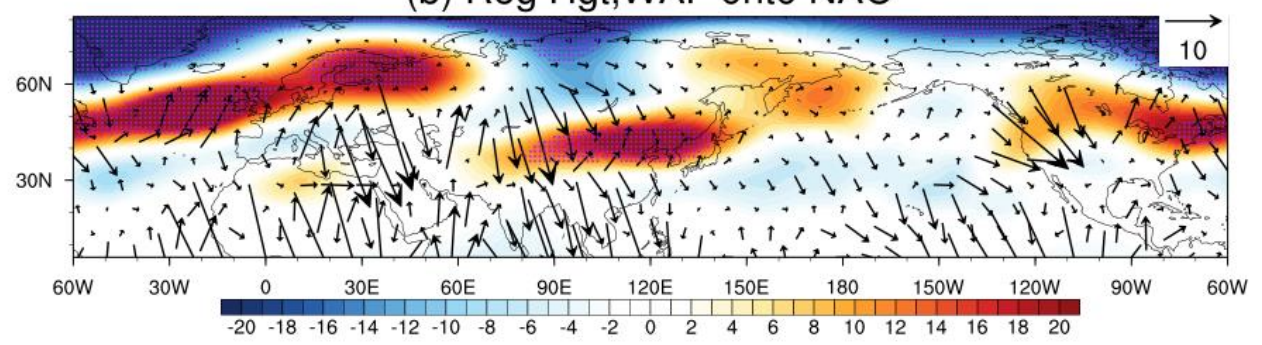


(c) PC2,oPC2 \& NAO

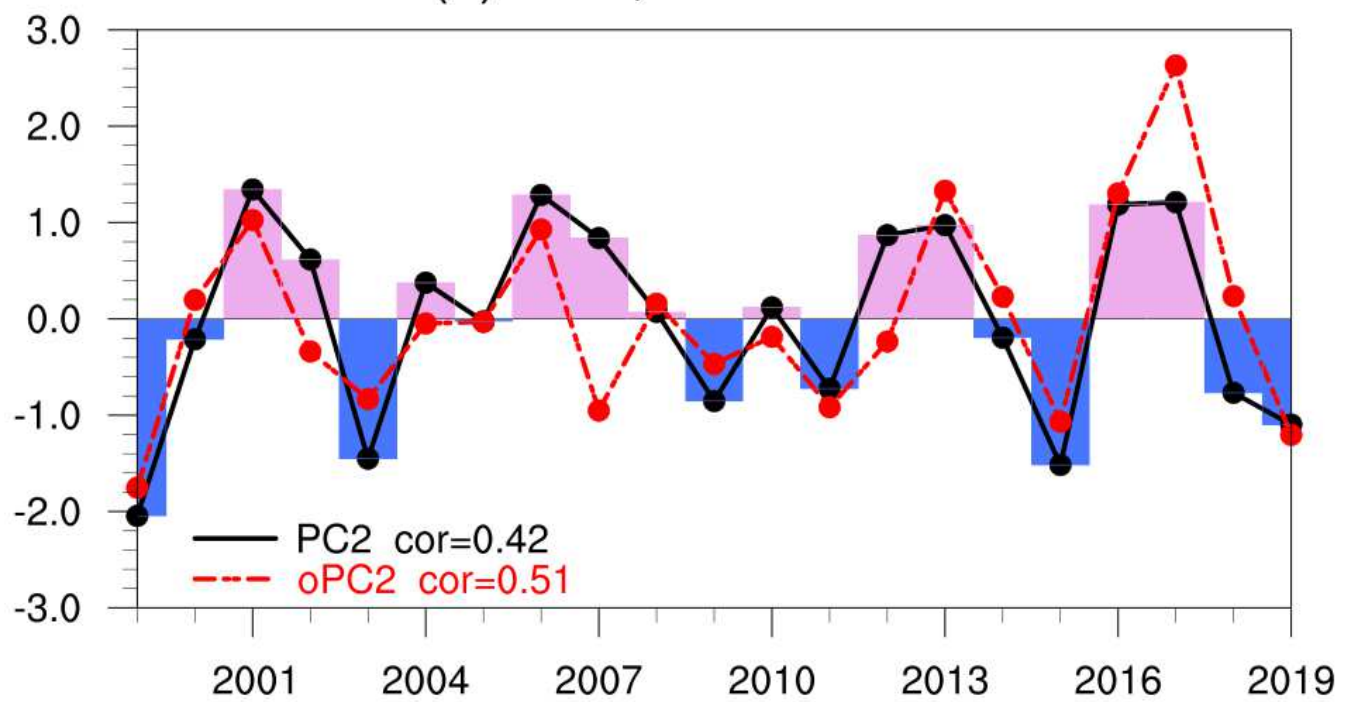

Fig.10 Regression maps of GH200 (Units: gpm) and wave activity flux (Units: $\mathrm{m}^{2 *} \mathrm{~s}^{-2}$ ) onto the PC2 (a) and NAO index (b). (c) NAO index (bar), PC2 (black solid) and oPC2 (red dashed).

Stippled areas indicate the significant values exceeding the $90 \%$ confidence levels

\section{Summary and discussion}

This study investigates the performance of ECMWF, which is the world's best dynamic model at subseasonal-seasonal timescale, about midsummer T2m over Eastern China. It further analyzes the predictable patterns of temperature anomalies based on the MSN EOF method and corresponding predictable sources and underlying mechanisms. EMCWF model and Obs have high similar modalities in climatological mean and the standard deviation of $\mathrm{T} 2 \mathrm{~m}$. Both the highest temperature mean and larger standard deviations are located in the middle and lower reaches of the YRV, and low temperatures and small standard deviation in the north parts, but EMCWF underestimates the climatological mean and interannual variability in southeast China. ECMWF and Obs have very different patterns of temperature trends. Obs shows a weakening trend in NC and SC, and an increasing trend in the middle Huanghuai Basin. However, the model shows an increasing trend in most areas, with the most intense in the north.

The first predictable pattern of T2m in ECMWF model is characterized by the dipole with lower temperature in the north and higher temperature in the south, showing a significant correlation with ENSO. In the transition phase from El Niño to La Niña, the WPSH is stronger and westward, and southern China is controlled by an abnormal anticyclone. Simultaneously 
southwest monsoon brings more water vapor to the north of YRV. These create the temperature mode that is colder in the north and warmer in the south. Although ECMWF captures the relationship between El Niño and this temperature mode, the weak correlation between WPSH and SSTAs makes it impossible to perfectly reproduce the physical process. The second mode is mainly the strong positive pattern in the YRV, and NAO is its most important early signal. In the positive phase of NAO, there is a dipole circulation pattern over the North Atlantic Ocean. The abnormal high pressure extended to northwestern Russia, subsequently inducing an abnormal wave train propagating to the southeast. Influenced by that, an abnormal high pressure formed in the lower reaches of the YRV to Northeast Asia, which caused the temperature anomalies in the second mode. For the leading two modes, high temperature is accompanied by local high pressure, precipitation reduction and solar radiation increase. The sinking airflow and less cloud cover strengthen the non-adiabatic heating and increase the surface temperature, meanwhile less precipitation promotes this process, and vice versa. The third mode is mainly the temperature trend term predicted by the model.

Although ECMWF S2S model has high skills beyond the weather timescale, and catches the early signal sources corresponding to predictable patterns of $\mathrm{T} 2 \mathrm{~m}$, but there are still ambiguous or unknown mechanisms within the model, which shows potential for improvement in the dynamic or statistical prediction of the S2S time scale. For example, Fig. 8c clearly shows that the relationship between ECMWF model and Obs for WPSH had undergone obvious interdecadal changes, with obvious synchronization in the middle period, but after 2013, they had almost the opposite interannual changes. And the surface air temperature may be affected by many other factors, such as that Arctic warming affects different modes of temperature by changing the propagation speed of Rossby waves (Francis and Vavrus 2012; Screen and Simmonds 2014), and the third trend mode may be affected by Anthropogenic factors such as greenhouse gases (Kang and Eltahir 2018). The prediction of extended weather timescale will be the frontier field of atmospheric research for a long time. we are extremely grateful to the anonymous reviewers for their valuable comments on this paper. 
This research is supported by the National Natural Science Foundation of China (41875101, 41805060) and the National Key R\&D Program of China (2017YFC1502303).

\section{References}

Allen MR, Smith LA (1997) Optimal filtering in singular spectrum analysis. Physics Letters A $234: 419-428$

Ambaum M, Hoskins BJ, Stephenson DB (2001) Arctic Oscillation or North Atlantic Oscillation? J Clim 14(16):3495-3507

440 Andrade FD, Coelho C, Cavalcanti I (2018) Global precipitation hindcast quality assessment of the Subseasonal to Seasonal (S2S) prediction project models. Clim Dyn 52(9-10):5451-5475

Barriopedro D, EM Fischer, J Luterbacher, RM Trigo, R García-Herrera (2011) The hot summer of 2010: Redrawing the temperature record map of Europe. Science 332(6026): 220-224

Chang CP, Zhang YS, Li T (2000) Interannual and interdecadal variations of the East Asian summer monsoon and tropical Pacific SSTs. PartI: Roles of the subtropical ridge. J Clim $13: 4310-4325$

Chen RD, Lu R (2015) Comparisons of the circulation anomalies associated with extreme heat in different regions of Eastern China. J Clim 28(14):5830-5844

Chen RD, Wen Z, Lu R (2017) Evolutions of the circulation anomalies and the quasi-biweekly oscillations associated with extreme heat events in South China. J Clim 31:213-232. https://doi.rog/10.1175/JCLI-D-17-0232.1

Coumou D, S Rahmstorf (2012) A decade of weather extremes. Nat Climate Change 2:491-496

Deng KQ, Yang S, Ting MF, et al (2019) Dominant modes of China summer heat waves driven by global sea surface temperature and atmospheric internal variability. J Clim, 32:3061-3075

Easterling DR (2000) Climate Extremes: Observations, modeling, and impacts. Science 289(5487):2068-2074

Fouillet A, Coauthors (2006). Excess mortality related to the August 2003 heat wave in France. International Archives of Occupational and Environmental Health 80(1):16-24

Francis JA, Vavrus SJ (2012) Evidence linking Arctic amplification to extreme weather in midlatitudes. Geophys Res Lett 39(6): L06801. https://doi.rog/10.1029/2012GL051000 
Gu S, Huang C, Bai L, Chu C, Liu Q (2016) Heat-related illness in China, summer of 2013. International Journal of Biometeorology 60(1):131-137

Guo XJ, Huang JB, Luo Y, et al (2017) Projection of heat waves over China for eight different global warming targets using 12 CMIP5 models. Theor Appl Climatol 128:507-522 Atlantic SST and the summertime western North Pacific subtropical high after the early 1980s. J Geophys Res Atmos 119:(7)3715-3722

Hu ZZ, Huang B (2007) The predictive skill and the most predictable pattern in the tropical Atlantic: the effect of ENSO. Mon Weather Rev 135:1786-1806

Hudson D, Alves O, Hendon HH, Marshall AG (2011) Bridging the gap between weather and seasonal forecasting: intraseasonal forecasting for Australia. Q J R Meteorol Soc 137:673689

Kang S, EA Eltahir (2018). North China Plain threatened by deadly heatwaves due to climate change and irrigation. Nature communications 9, 2894. https://doi.rog/10.1038/s41467-018$05252-\mathrm{y}$

Li JP, Ruan C (2018) Corrigendum: The North Atlantic-Eurasian teleconnection in summer and its effects on Eurasian climates. Environ Res Lett 13(2):129501. https://doi.rog/10.1088/17489326/aa9d33

Li JP, Fei Z, Cheng S, et al (2019) Pathways of Influence of the Northern Hemisphere Mid-high Latitudes on East Asian Climate: A Review. Adv Atmos Sci 36: 902-921

Liang JY, Yang S, Hu ZZ, et al (2009) Predictable patterns of the Asian and Indo-Pacific summer precipitation in the NCEP CFS. Clim Dyn 32(7-8):989-1001

Lu RY, Dong BW (2005) Impact of Atlantic sea surface temperature anomalies on the summer climate in the western North Pacific during 1997-1998. J Geophys Res Atmos 110(D16). https://doi.rog/10.1029/2004JD005676

Papalexiou SM, Aghakouchak A, Trenberth KE, et al (2018) Global, regional, and megacity trends in the highest temperature of the year: Diagnostics and evidence for accelerating trends. Earths Future 6(1): 71-79 
Rey G, A Fouillet, P Bessemoulin, P Frayssinet, A Dufour, E Jougla, D Hémon (2009) Heat exposure and socioeconomic vulnerability as synergistic factors in heat-wave related mortality. Eur J Epidemiol 24: 495-502

Screen JA, Simmonds I (2014) Amplified mid-latitude planetary waves favour particular regional weather extremes. Nat Clim Change 4(8):704-709

495 Sun Y, Zhang X, Zwiers FW, et al (2014) Rapid increase in the risk of extreme summer heat in Eastern China. Nat Clim Change 4:1082-1085

Tseng KC, Barnes EA, Maloney ED (2018) Prediction of the midlatitude response to strong Madden-Julian oscillation events on S2S timescales. Geophys Res Lett 45(12). https://doi.rog/10.1002/2017GL075734

Venzke S, Allen MR, et al (1999) The atmospheric response over the North Atlantic to decadal changes in sea surface temperature. J Clim 12:2562-2584

Vitart F, Robertson AW, Anderson DLT (2012) Subseasonal to seasonal prediction project: bridging the gap between weather and climate. WMO Bull 61(2):23-28

Vitart F (2017) Madden-Julian Oscillation prediction and teleconnections in the S2S database. Quarterly Journal of the Royal Meteorological Society, 143(706). https://doi.rog/10.1002/qj.3079

Wang B, Wu RG, Fu XH (2000) Pacific East Asian teleconnection: How does ENSO affect East Asian climate? J Climate 13:1517-1536

Wang PY, Tang JP, Sun XG, et al (2017). Heat waves in China: Definitions, leading patterns, and connections to large-scale atmospheric circulation and SSTs. J Geophys Res: Atmos 122(20):679-699

Wang PY, Tang JP, Wang SY, et al (2018) Regional heatwaves in China: a cluster analysis. Clim Dyn 50:1901-1917

Wang WW, Zhou W, Wang X, et al (2013) Summer high temperature extremes in Southeast China associated with the East Asian jet stream and circumglobal teleconnection. J Geophys Res: Atmos 118(15):8306-8319

Wang WW, Zhou W, Li XZ, et al (2016) Synoptic-scale characteristics and atmospheric controls of summer heat waves in China. Clim Dyn 46:2923-2941 
White CJ, Carlsen H, Robertson AW, et al (2017) Potential applications of subseasonal-to-seasonal (S2S) predictions. Meteorological Applications, 24(1). https://doi.rog/10.1002/met.1654

Xie SP, Jan H, Hiroki H, et al (2009) Indian Ocean capacitor effect on Indo-Western Pacific climate during the summer following El Niño. J Climate 22:730-747

Zhang LS, Xue JJ, Wang WG, et al (2014) Comparative analysis of extreme high temperature weather in the summers of 2013 and 2003. Atmos Oceanic Sci Lett 7:132-136

525 Zhou Y, Yang B, Chen H, et al (2019) Effects of the Madden-Julian Oscillation on 2-m air temperature prediction over China during boreal winter in the S2S database. Clim Dyn 52(11):1-19 